\title{
The Incidence, Pathology of Trauma and Victim Profiles of Homicidal Deaths in Pretoria, South
}

Africa (2007-2008)

\author{
Jeannie Cocks BScHons (Med Crim), Gert Saayman MMed (Med Forens)
}

Department of Forensic Medicine, University of Pretoria, PO Box 2034, Pretoria 0001, South Africa

Correspondence: Jeannie Cocks. Postal address: PO Box 1381 Bedfordview 2008. Email:

jeaniusofthelamp@hotmail.com

\section{DECLARATIONS}

Competing interests: The authors declare no conflict of interest.

Funding: Funding and sponsorship was neither sought nor obtained from any third parties. Only minor admin fees were incurred. The authors, Department of Forensic Medicine at the University of Pretoria and the Forensic Pathology Services covered the costs of printing, photocopying, phone calls and other similar costs.

Ethical approval: Approval for the study was obtained from the Students' Ethics Committee at the University of Pretoria. Permission to access the files at the Pretoria Medico-Legal Laboratory was obtained from the Facility Manager, Captain Dreyer and the CEO of Gauteng Mortuaries, Dr Mazizi.

Guarantor: I, Jeannie Cocks, nominate myself as the guarantor of the study: The Incidence, Pathology of Trauma and Victim Profiles of Homicidal Deaths in Pretoria, South Africa (2007-2008). I accept full responsibility for the work and conduct of the study. I had access to the data and controlled the decision to publish. I was actively involved in every step that went into the study, and I accept credit and accountability for each of these.

Contributorship: JC Designed the study, conducted the literature search and wrote the literature review to be included in the study protocol, compiled the protocol and data collection sheets, performed the data collection, conducted data analysis, interpreted the results and wrote all drafts of the article for publication. GS supervised the entire study process from inception to completion, aided 
in design of the study, aided in interpretation of the results and proofread each draft of the protocol, data collection sheets and eventual article for publication.

Acknowledgements: The authors would like to thank Dr Lorraine Du Toit-Prinsloo for her support and advice throughout the research process, and the staff at the Pretoria Medico-Legal Laboratory for their help relating to file access.

\section{ABSTRACT}

This study aimed to establish the incidence of homicide, associated pathology of trauma and victim profiles in cases admitted to or managed as homicidal deaths at the Pretoria Medico-Legal Laboratory (PMLL) over the period of 2007-2008. A total of 1088 cases were reviewed. Homicides accounted for $22.7 \%$ of all cases admitted to the PMLL. The majority of homicide victims were male individuals (87.0\%). The most common cause of death was gunshot wounds (42.6\%), followed by blunt force trauma $(25.1 \%)$. Homicides are most likely to occur at the victim's place of residence $(28.5 \%)$ and only $37.4 \%$ of victims survive long enough to receive hospital care. The results of this study seem to concur with international findings for the most part, with a few interesting deviations. Highlighting atrisk groups, as well as dangerous locations and incident times, creates the potential to decrease the occurrence of unnecessary deaths by generating an awareness of the trends.

\section{INTRODUCTION}

South Africa is persistently heralded as one of the crime capitals of the world. It is a notoriously violent country where crime and interpersonal violence are rife. According to the World Health Organisation, homicide is defined as any death resulting from injury purposely inflicted by another person (ICD9 codes 960-E978).

Homicide is the leading contributor to the injury burden placed on the public health system. ${ }^{1}$ Although our country's culture of political strife has been quelled somewhat, the incidence of interpersonal violence continues to be unacceptably high. ${ }^{2}$ The high homicide rates have been 
attributed to - among others - access to firearms, drugs and alcohol. ${ }^{3,4}$ There is a paucity of data reflecting these facts, however.

South Africa has a population of nearly 45 million, with its smallest province, Gauteng, playing host to almost nine million people. ${ }^{5}$ According to The South African Police Service, Gauteng has the highest rate of crime per capita. ${ }^{5}$ The population of Gauteng is composed of $73.8 \%$ Black Africans, $19.9 \%$ Whites, $3.8 \%$ coloureds and 2.5\% Indians/Asians ${ }^{\mathrm{a}}$ and has a male-to-female ratio of approximately 1:1.5. Within Gauteng, the city of Pretoria has a population of just over two million people. ${ }^{6}$ Although epidemiological studies regarding homicide are not uncommon internationally, it should be noted that a recent study of this nature had yet to be done for the Pretoria area.

Pretoria is the capital city of South Africa, although it is by no means the largest or most violent city in our country. In a recent Mexican study, the 50 most violent cities in the world were ranked. ${ }^{7}$ Four of South Africa's major cities made it onto this list, but the city of Pretoria did not feature. These points should be kept in mind when considering the data generated in this study.

This study aimed to establish the incidence of homicide, associated pathology of trauma and victim profiles in cases admitted to or managed as homicidal deaths at the Pretoria Medico-Legal Laboratory (PMLL) over the period of 2007-2008.

The PMLL caters to the greater part of the Pretoria area (admitting approximately 2500 cases per annum), with a smaller portion of the caseload (in the region of 1500 per annum collectively) being admitted to two other medicolegal facilities. ${ }^{6}$ According to the Inquests Act (Act No. 58 of 1959), all deaths due to other than natural causes are subjected to medicolegal investigation. ${ }^{6}$ The PMLL performs postmortem examinations in keeping with this Act.

\footnotetext{
a It is recognized that the terms 'Black', 'White', 'Coloured', 'Indian' and 'Asian' are social classifications of various population groups and have no scientific basis.
} 
It was envisaged that this study would (1) provide insight into the current situation regarding homicidal deaths in Pretoria, South Africa, and (2) facilitate national and international comparisons.

\section{MATERIALS AND METHODS}

A retrospect, descriptive case audit was conducted at the PMLL for all cases admitted to or managed as homicides during the period of 2007-2008. This study was aimed at the demographic profiles of the victims of homicide admitted to the PMLL, the associated pathology of trauma and other significant details pertaining to the circumstances surrounding the deaths.

Cases of road-traffic accidents which may lead to a charge of culpable homicide; so-called 'Section 48' deaths (according to the Health Professions Amendment Act, Act No. 29 of 2007) which do not suggest any deviation from sound medical practice; and abandoned babies and decomposed bodies with no overt signs of injury, were not considered in this study. Cases of rape-homicide, homicidesuicides and any other unusual deaths and details were also noted.

In order to identify the relevant cases, the admissions register, individual case files including postmortem reports and National Injury Mortality Surveillance Survey (NIMSS) forms were reviewed. NIMSS is a mortuary-based survey of mortalities resulting from external causes. ${ }^{6}$ It is designed to gather basic information and provide comprehensive baseline data regarding violencerelated deaths that undergo medicolegal investigation. ${ }^{6,8}$

The data used in this study depended on the completeness of the records at the PMLL, which were considered to be generally comprehensive and reliable.

\section{RESULTS AND DISCUSSION}

According to Medical Research Council (MRC) statistics, an average of 89 murders is committed each day in South Africa. ${ }^{3}$ This is an embarrassing statistic and the burden it places on our society is significant. Unfavourable comparisons with other INTERPOL-member countries led the South African government in 2004 to aim for a $7-10 \%$ per annum reduction in the occurrence of contact crimes (crimes against the person). ${ }^{4}$ 
Disparities often exist between data collected by medical examiners and that collected and represented by other agencies responsible for public reports. ${ }^{8}$ The data supplied in these reports are collected at points distant to their origin. Data of this nature are often incomplete or lacking sufficient detail to generate a true representation of the extent of violence in a particular community. ${ }^{8}$ The data gathered in this study come from the point of contact and are based on the individual assessments of the pathologists; aiming to provide a more realistic view of homicide statistics.

\section{Number of victims}

In 2007, the PMLL managed 494 cases of homicide, and in 2008, it managed 594 cases, with a total of 1088 cases of homicide (22.7\%) out of the 4800 total case load admitted to the mortuary over the two-year period. These values alone set a strong contrast to international statistics. A study conducted by Lee-Gorman et $a l .{ }^{9}$ in Ireland (with a population more than double that of the city of Pretoria) reported a total of 310 homicide victims over a five-year period. Similar studies reported 290 homicide victims between 1996 and 2005 in Hong Kong ${ }^{10}$ and 61 homicides between 1993 and 2003 in Manipal. ${ }^{11}$ This shines an embarrassing light on our country.

\section{Age, race and gender of victim}

The general consensus the world-over is that the typical homicide victims are young male individuals between the ages of 15 and 29 years. ${ }^{8}$

The homicide rates for 15- to 29-year-old South African male individuals are nine times the global rate, and our rates of female homicide are almost as excessive. ${ }^{2}$ Figure 1 shows the age distribution of the victims. The majority (41.0\%) of victims are in the age group of 21-30 years, which concurs with

other studies. ${ }^{11-13}$ About $7.9 \%$ of victims were found to be younger than 20 years of age and $8.7 \%$ were older than 50 years of age. The ages of $6.2 \%$ of victims were unknown.

The racial distribution of the victims does not appear to deviate greatly from the expected population make-up in South Africa. Eighty-three per cent of victims were Black, 12.0\% were White and Asian 
and Coloured comprised $1.5 \%$ and $3.0 \%$, respectively. The race of eight victims $(0.7 \%)$ was unknown.

According to other studies, ${ }^{9,11,13,14}$ male individuals account for $\sim 80 \%$ of cases of homicide, with rates more than three times those of female individuals. ${ }^{8,12}$ Some studies quote more even distributions, but always with a greater proportion of male victims. ${ }^{10,15}$ Similarly, in this study, there is a preponderance of male victims, with the results reporting a slightly higher value $(87.0 \%)$ than the $80 \%$ reported in other studies. ${ }^{9,11,13,14}$ Only one victim's sex was unknown.

\section{Location of incident}

Of all the data considered, this information was the most imprecise and infrequently recorded. This information is often lost or unreliable if the deceased went to hospital following the incident (i.e. the body was not collected from the scene by a forensic officer). The location of the incident was recorded in $63.6 \%$ of the cases $(n=692)$. Of these, it was found that most attacks occurred at the victim's place of residence (28.5\%). This finding mirrors those of other studies. ${ }^{9,15,16}$ Streets $(23.6 \%)$ and squatter camps/informal settlements (17.8\%) also see many homicide incidents in the Pretoria area. Figure 2 shows this distribution.

\section{Day of the week}

Day of the week of the incident was noted in $77.7 \%$ of cases $(n=845)$. As seen in Figure 3, homicides tended to occur over weekends, particularly Saturdays (26.1\%). This weekend trend was also found in studies such as those conducted in India ${ }^{11}$ and Finland. ${ }^{16}$ Thursdays presented the fewest incidents $(8.0 \%)$ contrary to one study conducted in Penang Island where Thursdays showed the highest number of incidents. ${ }^{12}$

\section{Month of the year}

Month of the incident was only noted in $852(78.3 \%)$ cases. The incidence of homicide was fairly evenly distributed over the months, ranging from $6.5 \%$ to $9.6 \%$. September $(6.5 \%)$ played host to the 
fewest homicide incidents, and slight peaks were seen in August (9.6\%), November $(9.4 \%)$ and December $(9.2 \%)$.

\section{Time of incident}

The time of the incident was only noted in $28.0 \%(\mathrm{n}=305)$ of the cases. Figure 4 represents this information. Peaks appear to be from the late evening (20:00) to the early morning (06:00), where $61.6 \%$ of homicides occurred, with a considerable dip during the daylight hours. This means that homicide in Pretoria is 1.6 times more likely to occur in the evening than during the day. Night time incidents were also found to be the most prevalent in other studies. ${ }^{9,11,13}$

\section{Medical attention}

Data regarding the degree of medical attention received by victims following the incident was available for 884 cases $(81.2 \%)$. Only approximately a third (37.4\%) of victims survived long enough to receive medical attention at a hospital, with half $(50.3 \%)$ receiving no medical attention at all before dying. About $12.2 \%$ of victims received some medical care at the scene of the incident before expiring.

\section{External cause of death}

As seen in Figure 5, the most common cause of death was gunshot wounds (42.6\%). This was followed by blunt force trauma $(25.1 \%)$ and sharp force trauma $(20.1 \%)$. These results are particularly noteworthy as they contrast strongly with the majority of international trends where blunt or sharp force injury take the lead as the major cause of homicidal death. ${ }^{9-13,15}$ Studies conducted by Fingerhut et $a l .{ }^{17}$ in the USA, Humayun et al. ${ }^{18}$ in Di Khan, and Marri et al. ${ }^{14}$ in Pakistan, however, also reported gunshot wounds as the leading cause of homicidal deaths in their study area.

\section{Blood alcohol levels}

Alcohol is often quoted as being strongly associated with the occurrence of violence and particularly, incidents of homicide. ${ }^{15,19}$ At the PMLL, alcohol screening is generally not conducted on very young 
victims or those who survived for more than 24 hours. Alcohol was tested on $86.3 \%$ of the victims (n =939). Of these 939 cases, $14.5 \%$ had alcohol levels between 0.01 and $0.1 \mathrm{~g} / 100 \mathrm{~mL}, 19.3 \%$ had levels between 0.11 and $0.2 \mathrm{~g} / 100 \mathrm{~mL}, 10.2 \%$ had levels between 0.21 and $0.3 \mathrm{~g} / 100 \mathrm{~mL}$ and $2.6 \%$ had levels exceeding $0.31 \mathrm{~g} / 100 \mathrm{~mL}$. Although $50.8 \%$ of cases tested negative for any traces of alcohol consumption prior to death, $32.1 \%$ were found to have been moderately to heavily $(0.11 \mathrm{~g} / 100$ $\mathrm{mL}$ ) intoxicated at the time of death. This appears to flag alcohol consumption as a risk factor for being a victim of violence.

\section{Additional findings}

There were 67 (6.2\%) cases of fatal mob justice assault during the study period. Interestingly, 51 of these occurred in 2008 alone. These numbers are likely to reflect the wave of xenophobic attacks that swept South Africa in 2008. ${ }^{20}$ There were only four $(0.37 \%)$ cases of homicide-suicide and one attempt, which was interrupted before the perpetrator could commit suicide. Rape-homicide alone is reported to be more prevalent in South Africa than all forms of female homicide in the United States. ${ }^{21}$ Rape was suspected to be an element of the crime in $32(2.9 \%)$ cases. It was also found that $6.2 \%$ of victims go unidentified.

\section{CONCLUSION}

Suspected incomplete reporting and inadequate data collection cause the official national mortality statistics to be subjected to much scrutiny. ${ }^{22}$ This suspicion serves to reinforce the need for studies to be conducted at the source: either to validate or challenge the official reports. ${ }^{22}$ This study aimed to gather the information directly from the point of contact, with trained medical professionals conducting the data collection. The Forensic Pathology Services officers collect the body at the scene and this is where data collection begins. This adds validity and reliability to the final records generated, aiding to dispel concerns over accuracy.

The most noteworthy findings from this study are that homicides comprise $\sim 20 \%$ of total admissions to the PMLL, approximately one in every 13 victims is under the age of 20 years and one in every 12 victims is over the age of 50 years. Perhaps the most noteworthy finding of all is the high occurrence 
of fatal gunshot wounds in cases of homicide, which contrasts strongly with the majority of international trends where blunt or sharp force injury take the lead as the major cause of homicidal death.

This study revealed large numbers over a limited study period, which in itself is worrying. Although the incidence of homicide in Pretoria seems staggering compared with international studies, one should also bear in mind that these numbers are likely to be conservative when compared with the notoriously more violent cities in our country, such as Cape Town. This only serves to highlight the severity of the situation in our country and calls for similar future studies to be done.

The data collected in this study serve as a benchmark for comparisons with other national and international homicide records. Emphasis is placed on the demographic factors presented in cases of homicidal death, with the aims of delineating any patterns regarding victim profiles. It serves to highlight at-risk groups and dangerous locations and incident times; with the potential to possibly decrease the occurrence of unnecessary deaths by creating an awareness of the trends, thereby allowing us to focus our limited policing resources on these vulnerable individuals. ${ }^{6}$ 


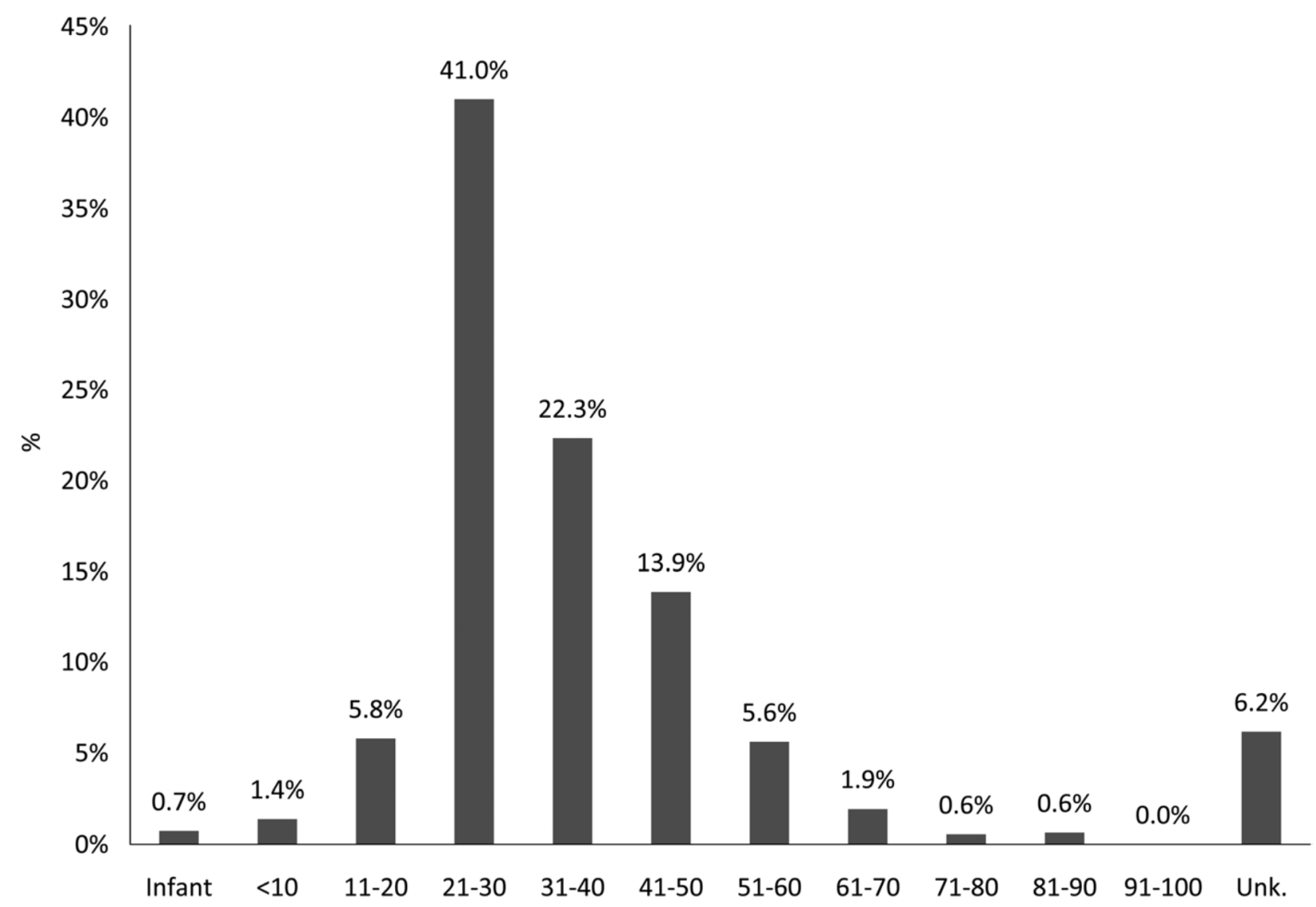

Figure 1. Age of victim $(\mathrm{n}=1088)$

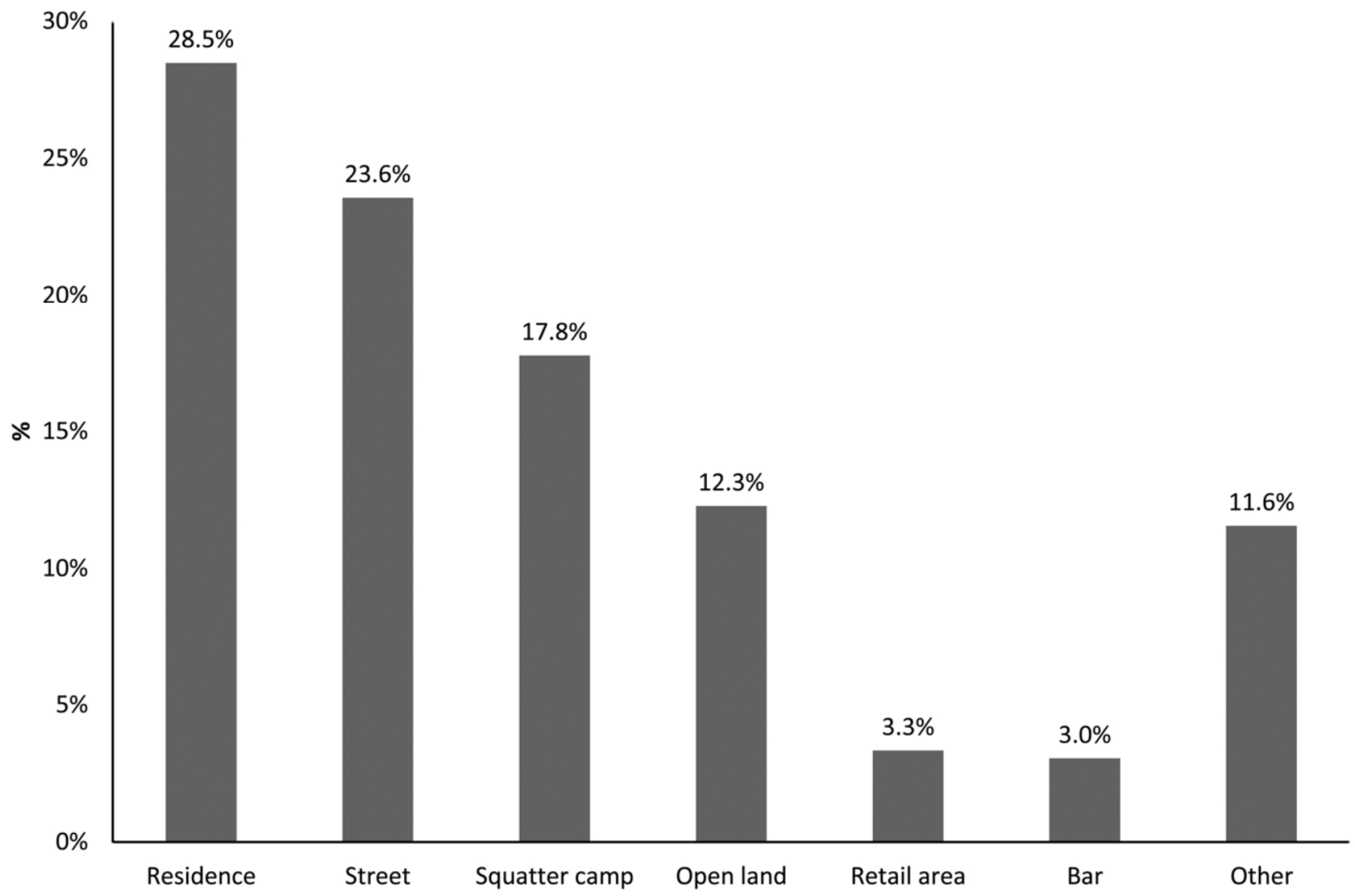

Figure 2. Location of incident $(\mathrm{n}=692)$ 


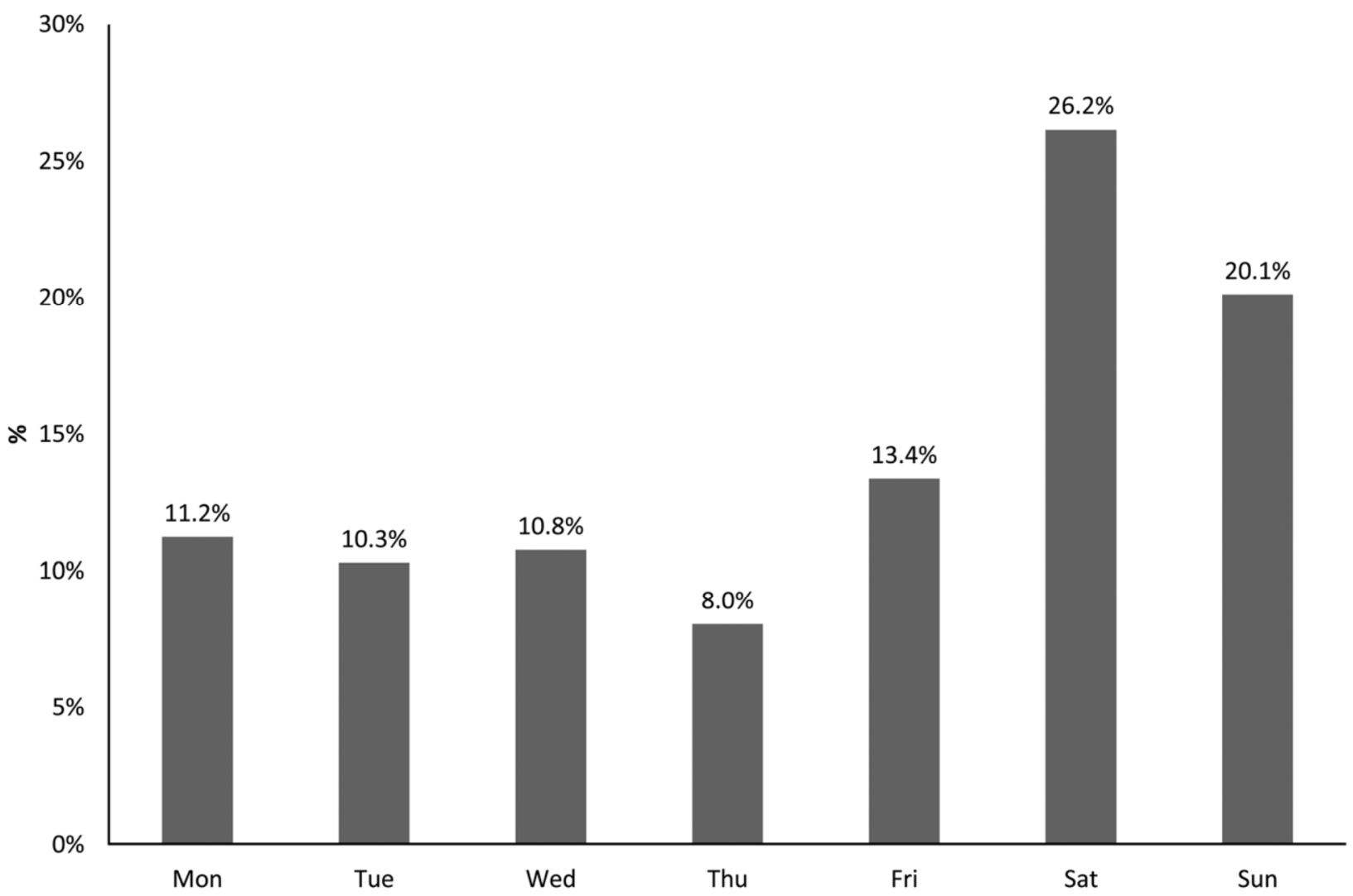

Figure 3. Day of the week $(\mathrm{n}=845)$

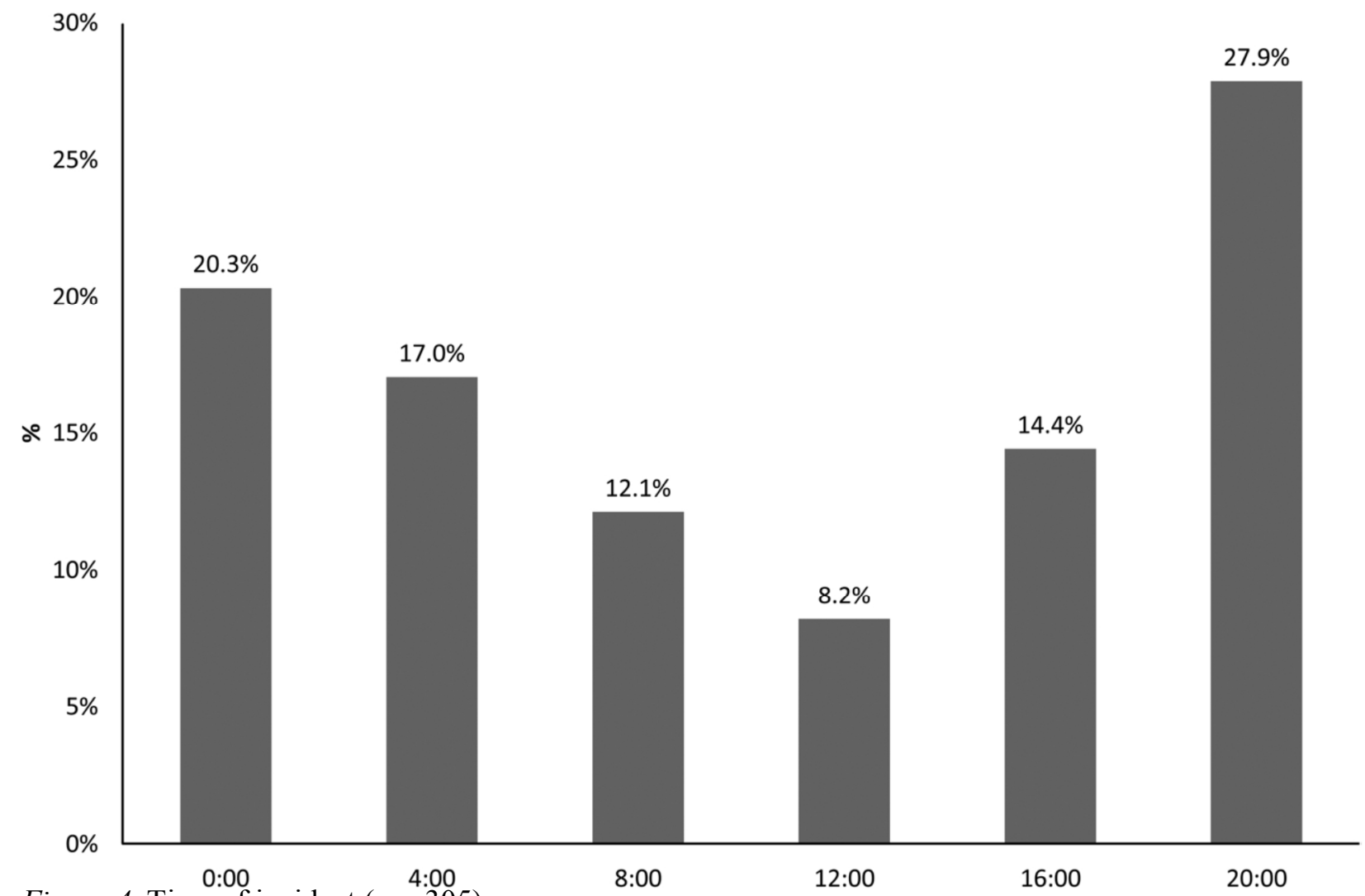

Figure 4. Time of incident $(\mathrm{n}=305)$ 


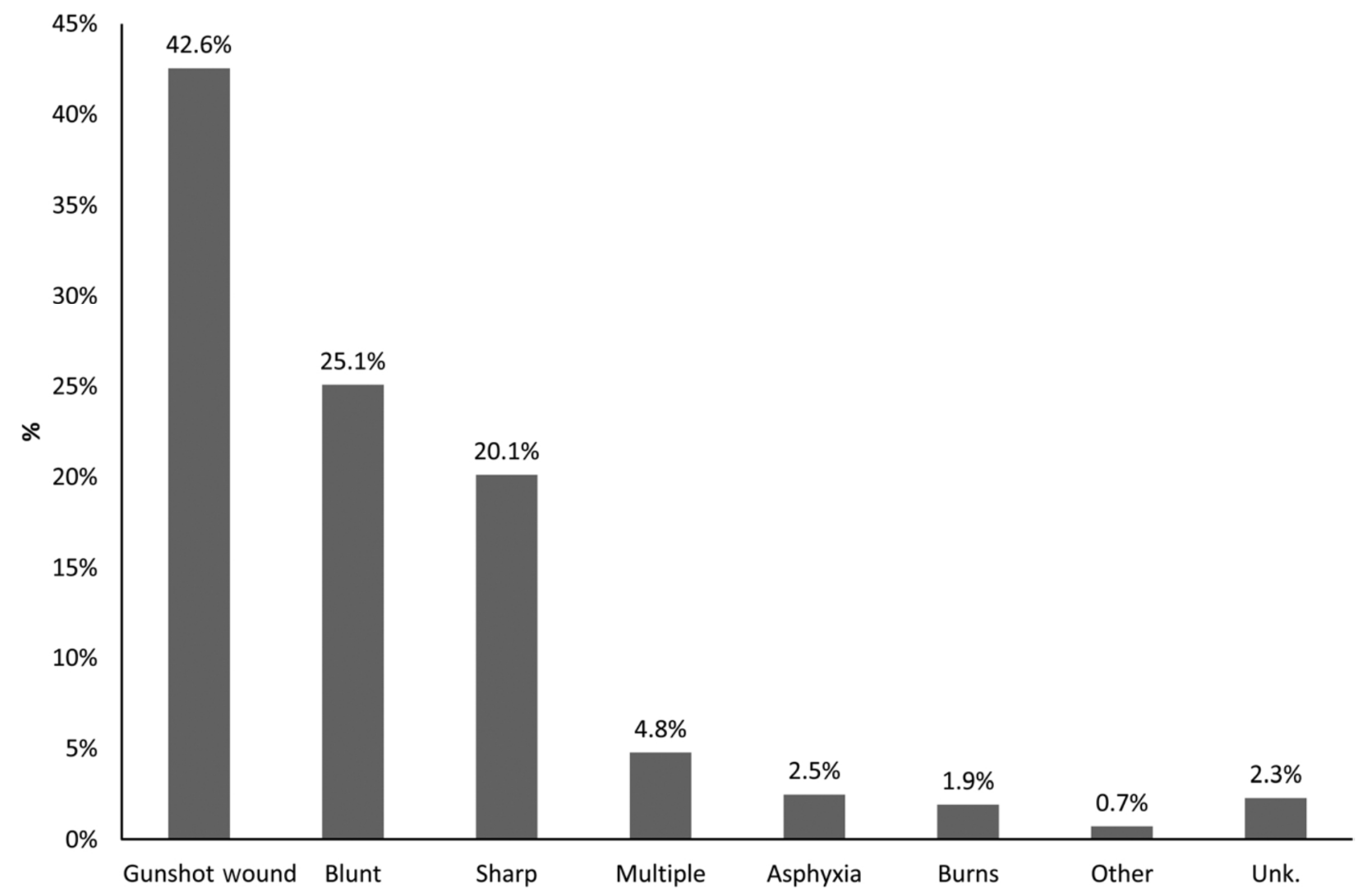

Figure 5. External cause of death $(\mathrm{n}=1088)$ 


\section{REFERENCES}

1. Butchart A, Brown D, Wilson A, Mikton C. Preventing Violence and Reducing Its Impact: How Development Agencies Can Help. Geneva: World Health Organisation, 2008

2. Norman R, Matzopoulos R, Groenewald P, Bradshaw D. The High Burden of Injuries in South Africa. See http://0-www.who.int.innopac.up.ac.za (last checked 27 February 2011)

3. Mc Cafferty R. Murder in South Africa: a Comparison of Past and Present. $1^{\text {st }}$ edn. United Christian Action, 2003

4. SAPS Strategic Management. SAPS Annual Report 2007/2008. South African Police Service, 2008

5. Census 2001: Census in brief. Pretoria: Statistics South Africa, 2003. See http://www.statssa.gov.za (last checked 27 February 2011)

6. Donson H, ed. A Profile of Fatal Injuries in South Africa. Ninth Annual Report of the National Injury Mortality Surveillance System. MRC-UNISA Crime, Violence and Injury Lead Programme, 2007

7. San Pedro Sula, la ciudad mas violent del mundo, jaurez, la segunda. Seguridad, Justicia y Paz, January 2012. See http://www. seguridadjusticiaypaz.org.mx (last checked 2 February 2012)

8. Krug EG, Dahlberg LL, Mercy JA, Zwi AB, Lozano R, eds. World Report On Violence and Health. Geneva: World Health Organisation, 2002

9. Lee-GormanM,MacNeill S, Rizet D,McDermott SD. Homicide/suspicious death statistics for cases submitted to the forensic science laboratory in the Republic of Ireland for 2004-2008. Med Sci Law 2011;51:146-50

10. Kwan-Ip A. An Autopsy-Based Retrospective Study of Injury Patterns of Homicides in Hong Kong: Injury Patterns, Severity, and Prediction of Relationship with the Offender. Thesis. Hong Kong University, 2008

11. Mohanty MK, Mohan Kumar TS, Mohanram A, Palimar V. Victims of homicidal deaths: an analysis of variables. J Clin Forensic Med 2005;12:302-4 
12. Bhupinder S, Kumara TK, Syed AM. Pattern of homicidal deaths autopsied at Penang Hospital, Malaysia, 2007-2009: a preliminary study. Malays J Pathol 2010;32:81-6

13. Gupta A, Rani M, Mittal AK, Dikshit PC. A study of homicidal deaths in Delhi. Med Sci Law $2004 ; 44: 127-32$

14. Marri MZ, Bashir MZ, Munawar AZ, Khalil ZH, Khalil IU. Analysis of homicidal deaths in Peshawar, Pakistan. J Ayub Med Coll Abbottabad 2006;18:30-3

15. Avis SP. Homicide in Newfoundland: a nine-year review. J Forensic Sci 1996;41:101-5

16. Wahlsten P, Koiranen V, Saukko P. Survey of medico-legal investigation of homicides in the city of Turku, Finland. J Forensic Leg Med 2007;14:243-52

17. Fingerhut LA, Ingram DD, Feldman JJ. Firearm and non-firearm homicides among persons 15 through 19 years of age. J Am Med Acad 1992;267:348-53

18. Humayun M, Khan D, Fasee-uz-Zaman, et al. Analysis of homicidal deaths on district Di Khan: an autopsy study. J Ayub Med Coll Abbottabad 2009;21(1):155-7

19. Goodman RA, Mercy JA, Loya F, et al. Alcohol use and interpersonal violence: alcohol detected in homicide victims. Am J Pub Health 1986;76(2):144-9

20. Conway-Smith E. The brutal murder of a Zimbabwean man by a mob of residents in the Diepsloot township in northern Johannesburg was caught on cell phone camera. News Desk 2011;04:15. See http://mobile.globalpost.com (last checked 29 December 2011)

21. Abrahams N, Martin LJ, Jewkes R, Mathews S, Vetten L, Lombard C. The epidemiology and the pathology of suspected rape homicide in South Africa. Forensic Sci Int 2008;178:132-8

22. Groenewald P, Bradshaw D, Daniels J, et al. Local-Level Mortality Surveillance in ResourceLimited Settings: A Case Study of Cape Town Highlights Disparities in Health. See http://0www.who.int.innopac. up.ac.za (last checked 27 February 2011) 